\title{
Celecoxib enhances sensitivity to chemotherapy drugs of T-cell lymphoma
}

\author{
MING MA $^{1 *}$, XINGXIAO YANG ${ }^{2 *}$, LIANMEI ZHAO ${ }^{3}$, XUEXIAO WANG $^{3}$, LIHUA LIU $^{3}$, \\ WENJING JIAO $^{1}$, YUANYUAN WEI ${ }^{1}$ and BAOEN SHAN ${ }^{3}$ \\ ${ }^{1}$ Clinical Laboratory; ${ }^{2}$ Department of Infection Management; ${ }^{3}$ Research Center, The Fourth Hospital of \\ Hebei Medical University, Shijiazhuang, Hebei 050011, P.R. China
}

Received July 16, 2016; Accepted December 19, 2017

DOI: $10.3892 / 01.2018 .7897$

\begin{abstract}
Celecoxib is a newly-identified nonsteroidal anti-inflammatory drug, which has been used to treat fever in clinical practice. Celecoxib has been demonstrated to suppress the viability of various human tumor cells. However, the effect of celecoxib on response of T-cell lymphoma to chemotherapy agents remains unclear. The aim of the present study was to investigate the effect of celecoxib on chemosensitivity of human T-cell lymphoma, and to address the underlying mechanism of action. The cytotoxicity of CDDP, epirubicin and VCR on Jurkat and Hut-78 cells treated with celecoxib was assessed by MTT assay, and the half-maximal inhibitory concentration $\left(\mathrm{IC}_{50}\right)$ value was calculated by Origin 75 software. The effect of celecoxib on apoptosis and intracellular concentration of Rhodamine-123 in Jurkat and Hut-78 cells was analyzed by flow cytometry. The expression of transcription factor p65 (p65), B-cell lymphoma 2 (Bcl-2), Bcl-2-associated $\mathrm{X}$ protein (Bax), multidrug resistance 1 (MDR1) and multidrug resistance-associated protein 1 (MRP1) at mRNA and protein levels were detected by reverse transcription quantitative polymerase chain reaction and western blotting, respectively. Proliferation suppression rates and apoptosis levels were significantly increased in Jurkat and Hut-78 cells combined with celecoxib compared with those without celecoxib, when treated with CDDP, epirubicin and VCR. The $\mathrm{IC}_{50}$ values of the chemotherapy agents were lower in Jurkat and Hut-78 cells treated with celecoxib compared with those that were not.
\end{abstract}

Correspondence to: Professor Baoen Shan, Research Center, The Fourth Hospital of Hebei Medical University, 12 Jiankang Road, Shijiazhuang, Hebei 050011, P.R. China

E-mail: shanbaoen@163.com

*Contributed equally

Abbreviations: CDDP, cis-diamminedichloroplatinum; VCR, vinblastine; $\mathrm{IC}_{50}$, half-maximal inhibitory concentration; MDR, multidrug resistance

Key words: celecoxib, chemotherapy sensitivity, T-cell lymphoma, multidrug resistance
The apoptosis level, expression of Bax and the intracellular concentration of Rhodamine-123 were increased, whereas the expression of p65, Bcl-2, MDR1 and MRP1 were decreased, in celecoxib-treated Jurkat and Hut-78 cells compared with those without celecoxib treatment. These results indicated that celecoxib may enhance the sensitivity of T-cell lymphoma to chemotherapy drugs by inhibiting the expression of multidrug resistance (MDR)-associated proteins via downregulating the activity of the nuclear factor- $\mathrm{\kappa} B$ signaling pathway, suggesting that celecoxib may improve the curative effect of chemotherapy drugs in T-cell lymphoma.

\section{Introduction}

T-cell lymphoma is the one of the most common immune subtypes of hematopoietic malignancy originating from lymphoid tissues, accounting for $\sim 15 \%$ of all non-Hodgkin's lymphoma in China between 2000 and 2014 (1). At present, chemotherapy agents-based strategies remain the first choice for treatment of T-cell lymphoma, however poor prognosis is inevitable due to the occurrence of multidrug resistance (MDR) (2). The typical MDR phenotype is characterized by the overexpression of the MDR-associated proteins in the cytomembrane that serve as efflux pumps, to exclude the intracellular antitumor agents $(3,4)$. As the prognosis of patients with T-cell lymphoma is greatly impaired by MDR, novel strategies to alleviate drug resistance and improve survival rates are urgently required.

Celecoxib is a newly-identified nonsteroidal anti-inflammatory drug, which is used to treat fever in clinical practice (4). Previously, celecoxib was demonstrated to induce apoptosis in multiple malignant tumor cells, but to have less toxicity and side effects on normal tissue cells (3). Celecoxib was identified to enhance the chemosensitivity and reduce the incidence of acquired MDR in human gastric, colon and breast carcinomas (4). Considering the function of celecoxib in reversing MDR in digestive and gynecologic tumors, we hypothesize that celecoxib may increase the chemosensitivity of T-cell lymphoma.

To the best of our knowledge, the present study revealed, for the first time, that celecoxib enhanced the inhibition effect of conventional chemotherapy drugs on T-cell lymphoma cell lines and significantly increased the percentages of apoptotic 
cells. The half maximal inhibitory concentration $\left(\mathrm{IC}_{50}\right)$ of the representative chemotherapy agents cis-diamminedichloroplatinum (CDDP), epirubicin and vinblastine (VCR) was significantly decreased in T-cell lymphoma cells treated with celecoxib compared with those that were not. Additionally, the expression levels of MDR-associated proteins P-glycoprotein (P-gp), multidrug resistance-associated protein 1 (MRP1), transcription factor p65 (p65) and B-cell lymphoma 2 (Bcl-2) were decreased, whereas the expression level of Bcl-2-associated $\mathrm{X}$ protein $(\mathrm{Bax})$ was increased in celecoxib-treated T-cell lymphoma cell lines compared with those that were not treated with celecoxib. By investigating the effect of celecoxib on T-cell lymphoma cells, it was identified that celecoxib may reduce drug resistance in these cells by inactivating the nuclear factor $(\mathrm{NF})-\kappa \mathrm{B}$ pathway. These data indicate that the combination of celecoxib and chemotherapy drugs may be an effective treatment strategy to improve the curative effect of chemotherapy drugs in T-cell lymphoma.

\section{Materials and methods}

Cell lines and regents. The human T-cell lymphoma Jurkat and HuT-78 cell lines were supplied by the Research Center of the Fourth Hospital of Hebei Medical University (Shijiazhuang, China) and cultured in RPMI-1640 complete medium (Sigma-Aldrich; Merck KGaA, Darmstadt, Germany) containing 10\% fetal calf serum (FCS; Gibco; Thermo Fisher Scientific, Inc., Waltham, MA, USA) at $37^{\circ} \mathrm{C}$ in a humidified incubator with $5 \% \quad \mathrm{CO}_{2}$. The Annexin V-fluorescein isothiocyanate (FITC) and propidium iodide (PI) double stain kit was supplied by BD Pharmingen; BD Biosciences (San Jose, CA, USA). Rabbit anti-human antibodies against p65 (cat. no. ,76311), P-gp (cat. no. ,168337) and MRP1 (cat. no. ,84320) were obtained from Abcam (Cambridge, MA, USA). Rabbit anti-human antibodies against Bcl-2 (cat. no. ,12789-1-AP) and Bax (cat. no. ,50599-2-Ig) were purchased from ProteinTech Group, Inc. (Chicago, IL, USA). Rabbit anti-human antibodies against $\beta$-actin (cat. no. ,AP0060) were obtained from Bioworld Technology, Inc. (St. Louis Park, MN, USA). The horseradish peroxidase (HRP)-conjugated goat anti-rabbit secondary antibody (cat no. 29527) was purchased from Rockland Immunochemicals Inc. (Limerick, PA, USA). TRIzol ${ }^{\circledR}$ reagent was obtained from Life Technologies (Thermo Fisher Scientific, Inc.). MTT, Rhodamine-123 and Ficoll separating medium (density: $1.077 \mathrm{~g} / \mathrm{ml}$ ) were purchased from Sigma-Aldrich; Merck KGaA. Go Taq ${ }^{\circledR}$ qPCR Master Mix was purchased from Promega Corporation (Madison, WI, USA). The RevertAid ${ }^{\mathrm{TM}}$ First Strand cDNA Synthesis kit was purchased from MBI Fermentas; Thermo Fisher Scientific, Inc. CDDP was purchased from Qilu Pharmaceutical Co.,Ltd. (cat no.,EA4A7039A; Jinan, China). Epirubicin was purchased from Hisun Pharmaceutical Co., Ltd. (cat no., 17035211; Taizhou, China). VCR was purchased from Shenzhen Main Luck Pharmaceuticals Inc., (cat. no. ,1608V3; Shenzhen, China). Celecoxib was purchased from Pfizer, Inc. (New York, NY, USA; cat. no. ,S52338).

MTT assay. The effect of celecoxib on cell viability of Jurkat and Hut-78 cells was evaluated by the MTT assay. The Jurkat and Hut-78 cells were plated at a density of $1 \times 10^{5}$ cells/well in
$200 \mu 1$ RPMI-1640 medium supplemented with 10\% FCS and treated with celecoxib (20, 40 and $80 \mu \mathrm{mol} / \mathrm{l})$ in 96-well plates (Gibco; Thermo Fisher Scientific, Inc.). As a control, Jurkat and Hut-78 cells were not treated with celecoxib. Following incubation for 24,48 and $72 \mathrm{~h}$ at $37^{\circ} \mathrm{C}$ in a humidified incubator, $10 \mu \mathrm{l}$ MTT solution [5 $\mathrm{mg} / \mathrm{ml}$ in phosphate-buffered saline (PBS)] was added to the cells, which were then incubated again for $4 \mathrm{~h}$ at $37^{\circ} \mathrm{C}$. Subsequently, $100 \mu \mathrm{l}$ DMSO was added to dissolve the formazan crystals. The absorbance at $492 \mathrm{~nm}$ was measured using a Titertek Multiskan ${ }^{\mathrm{TM}}$ microplate reader (Flow Laboratories, North Ryde, Australia) to assess the effect of celecoxib on cell viability.

Lymphocyte cell viability assay. The peripheral blood was extracted from 3 cases of healthy volunteers without carcinomas, cardiovascular and endocrine system diseases, who underwent routine physical examination at the Fourth Hospital of Hebei Medical University (Shijiazhuang, China) between April 2016 and May 2016. The median age of the volunteers was 39 years (range, 32-44 years). T lymphocytes was separated from peripheral blood of healthy volunteers ( 2 females and 1 male) by density gradient centrifugation $(240 \mathrm{x} g$ for $20 \mathrm{~min}$ ) at room temperature, using Ficoll separating medium (density: $1.077 \mathrm{~g} / \mathrm{ml}$ ). MTT assay was used to determine the cytotoxic effect of celecoxib on cell viability of $\mathrm{T}$ lymphocytes, as aforementioned. As a control, $\mathrm{T}$ lymphocytes were not treated with celecoxib. This research was approved by the ethic committee of the Fourth Hospital of Hebei Medical University and written informed consent was obtained from all participants.

Flow cytometry. The effect of celecoxib on the apoptosis level of Jurkat and Hut-78 cells was assessed by flow cytometry analysis. Jurkat and Hut-78 cells $\left(10^{6} / \mathrm{ml}\right)$ treated with celecoxib at different doses $(0,20,40$ and $80 \mu \mathrm{mol} / \mathrm{l})$ were incubated with $5 \mu \mathrm{l}$ Annexin V-FITC and PI double stain at room temperature for $15 \mathrm{~min}$. Following staining, cells were resuspended in ice-cold PBS and were analyzed using a flow cytometer (FACSCalibur ${ }^{\mathrm{TM}}$; BD Biosciences). Data were analyzed using CellQuest Pro version 5.1 software (BD Biosciences).

Western blotting analysis. Jurkat and Hut-78 cells treated with celecoxib at different doses $(0,20,40$ and $80 \mu \mathrm{mol} / \mathrm{l})$ were lysed with $500 \mu \mathrm{l}$ lysis buffer (1\% Triton X-100, $150 \mathrm{mM} \mathrm{NaCl}$, $10 \mathrm{mM}$ Tris- $\mathrm{HCl}$ at $\mathrm{pH}$ 7.4, $1 \mathrm{mM}$ EDTA, $1 \mathrm{mM}$ EGTA at $\mathrm{pH}$ 8.0, 0.2 mM Na3VO4, $0.2 \mathrm{mM}$ phenylmethyl sulphonyl fluoride and $0.5 \% \mathrm{NP}-40$ ). The protein concentration in the lysates was determined by BCA assay. The lysates were then subjected to western blotting analysis to determine the amount of P-gp, MRP1, Bcl-2, Bax, p65 and $\beta$-actin protein in cells. Briefly, the total proteins ( $40 \mu \mathrm{g}$ per well) were subjected to $10 \%$ SDS-PAGE and were electro-transferred onto a polyvinylidene difluoride membrane. The membranes were blocked in PBS containing 5\% FCS for $2 \mathrm{~h}$ at room temperature. Membranes were incubated with rabbit anti-human primary antibodies at different dilutions, including monoclonal antibodies to p65 (1:2,000), Bcl-2 (1:1,000), Bax (1:1,000), P-gp (1:1,000), MRP1 $(1: 1,000)$ and $\beta$-actin $(1: 5,000)$ for $8 \mathrm{~h}$ at $4^{\circ} \mathrm{C}$. The PVDF membranes were visualized in the Odyssey infrared imaging system, after incubation with HRP-conjugated goat anti-rabbit 
secondary antibodies $(1: 5,000)$ for $2 \mathrm{~h}$ at room temperature. The expression levels of these target proteins were calculated as the ratio of the intensity of the specified protein to that of $\beta$-actin, using Odyssey v3.0 software (LI-COR Biosciences, Lincoln, NE, USA).

$R N A$ preparation and reverse transcription quantitative polymerase chain reaction ( $R T-q P C R$ ) analysis. An RT-qPCR assay was used to evaluated the effect of celecoxib on expression of P65, Bcl-2, Bax, MDR1 and MRP1 mRNA in Jurkat and Hut-78 cells. Total RNA was extracted from Jurkat and Hut-78 cells treated with celecoxib at different doses (0, 20, 40 and $80 \mu \mathrm{mol} / \mathrm{l}$ ) using TRIzol reagent and the first strand cDNAs were generated from $1 \mu \mathrm{g}$ total RNA using RevertAid ${ }^{\mathrm{TM}}$ First Strand cDNA Synthesis kit and incubation at $42^{\circ} \mathrm{C}$ for $60 \mathrm{~min}$. The resultant cDNAs were amplified by RT-qPCR using GoTaq ${ }^{\circledR}$ qPCR Master. The specific primers sequences (Shanghai Generay Biotech, Co., Ltd., Shanghai, China) and annealing temperature for the target genes are summarized in Table I. The following thermocycling conditions were used for the PCR: $95^{\circ} \mathrm{C}$ for $10 \mathrm{~min}$; 40 cycles of $95^{\circ} \mathrm{C}$ for $15 \mathrm{sec}, 60^{\circ} \mathrm{C}$ for $15 \mathrm{sec}$ and $60^{\circ} \mathrm{C}$ for $1 \mathrm{~min}$. The relative level of expression of each target gene was assessed by the $2^{-\Delta \Delta \mathrm{Cq}}$ method (5).

Rhodamine-123 efflux assay. The rhodamine-123 efflux assay was performed to evaluate the efflux pump effect of P-gp and MRP1 in the Jurkat and Hut-78 cells treated with celecoxib at different doses $(0,20,40$ and $80 \mu \mathrm{mol} / \mathrm{l})$. The celecoxib-treated cells were co-cultured with Rhodamine-123 $(5 \mathrm{mg} / \mathrm{ml})$ for $1 \mathrm{~h}$ at room temperature and analyzed using a FACScan flow cytometer (FACSCalibur ${ }^{\mathrm{TM}}$, BD Biosciences) to analyze the intensity of fluorescence. Data were analyzed by CellQuest Pro version 5.1 software (BD Biosciences).

Statistical analysis. The data are reported as the mean \pm standard deviation. One-way analysis of variance was performed to determine the significance between groups. Turkey's method was used for multiple comparisons. $\mathrm{P}<0.05$ were considered to indicate a statistically significant difference. Experiments were repeated in triplicate. All statistical analyses were conducted using the SPSS software version 13.0 (SPSS, Inc., Chicago, IL, USA).

\section{Results}

Celecoxib may inhibit growth and enhance the sensitivity of T lymphocytes to chemotherapy drugs. Firstly, MTT assays were used to determine the inhibitory effect of celecoxib on the viability of T-cell lymphoma cells. As demonstrated in Fig. 1A, celecoxib significantly suppressed cell viability in Jurkat and Hut-78 cells in a time- and dose-dependent manner compared with the control group $(\mathrm{P}<0.05)$, indicating that celecoxib may markedly inhibit the proliferation of $\mathrm{T}$ lymphoma cells. Whether celecoxib had an additive effect on the response to chemotherapy agents in T-cell lymphoma was additionally explored. As demonstrated in Fig. 1B, the viability of Jurkat and Hut-78 cells over $24 \mathrm{~h}$ was dose-dependently suppressed by CDDP, epirubicin and VCR, with significantly increased inhibition observed in Jurkat and Hut-78 cells treated with chemotherapeutic drugs combined with celecoxib compared
Table I. Primer sequences and annealing temperature for the reverse transcription-quantitative polymerase chain reaction.

\begin{tabular}{|c|c|c|}
\hline Gene & Primer sequence & $\begin{array}{c}\text { Annealing } \\
\text { temperature, }{ }^{\circ} \mathrm{C}\end{array}$ \\
\hline$\beta$-actin & $\begin{array}{l}\text { F: 5'-GTTGTGATGGGTTC } \\
\text { TGA-3' } \\
\text { R: 5'-GAGCAATAGCGTCT } \\
\text { GTG-3' }\end{array}$ & 60 \\
\hline MRP1 & $\begin{array}{l}\text { F: 5'-CGCTGAGTTCCTGCGT } \\
\text { ACC-3' } \\
\text { R: 5'-TCTGCGGTGCTGTTG } \\
\text { TGG-3' }\end{array}$ & 60 \\
\hline MDR1 & $\begin{array}{l}\text { F: 5'-CAGAGGGGATGGTCAG } \\
\text { TGTT-3' } \\
\text { R: 5'-CGTGGTGGCAAACAATA } \\
\text { CAG-3' }\end{array}$ & 60 \\
\hline P65 & $\begin{array}{l}\text { F: 5'-GGCGAGAGGAGCACAG } \\
\text { ATAC-3' } \\
\text { R: 5'-ATCTTGAGCTCGGCAG } \\
\text { TGTT-3' }\end{array}$ & 60 \\
\hline Bcl-2 & $\begin{array}{l}\text { F: 5'-GTGAACTGGGGGAGGA } \\
\text { TTGT-3' } \\
\text { R: 5'-GGAGAAATCAAACAG } \\
\text { AGGCC-3' }\end{array}$ & 60 \\
\hline Bax & $\begin{array}{l}\text { F: 5'-GGCCGGGTTGTCGCCCT } \\
\text { TTT-3' } \\
\text { R: 5'-CCGCTCCCGGAGGAAG } \\
\text { TCCA-3' }\end{array}$ & 60 \\
\hline
\end{tabular}

F, forward; R, reverse; MRP1, multidrug resistance-associated protein 1; MDR1, multidrug resistance protein 1; P65, tumor protein 65; Bcl-2, B-cell lymphoma 2; Bax, Bcl-2-associated $\mathrm{X}$ protein.

with cells treated with chemotherapy drugs alone $(\mathrm{P}<0.05)$. Additionally, the $\mathrm{IC}_{50}$ values of chemotherapy agents were significantly reduced in Jurkat and Hut-78 cells treated with celecoxib in a dose-dependent manner compared with those that were not treated with celecoxib $(\mathrm{P}<0.05)$ (Fig. 1C). These results suggested that celecoxib may enhance the sensitivity of T-cell lymphoma cells to chemotherapy drugs. In contrast, the viability of normal $\mathrm{T}$ cells was not reduced following treatment with celecoxib at the different doses ( $\mathrm{P}>0.05)$ (Fig. 1D).

To additionally evaluate the facilitating effect of celecoxib on the chemosensitivity of T-cell lymphoma, flow cytometry analysis was performed to determine whether celecoxib induced apoptosis in Jurkat and Hut-78 cells. As demonstrated in Fig. 2, the apoptosis rate of Jurkat and Hut-78 cells treated with celecoxib was significantly increased compared with the cells in the control group $(\mathrm{P}<0.01)$, indicating that celecoxib-induced proliferation inhibition of lymphoma cells may be due to a pro-apoptotic effect. Furthermore, when Jurkat and Hut-78 cells were treated with chemotherapy agents combined with celecoxib, the percentage of apoptotic cells 
A

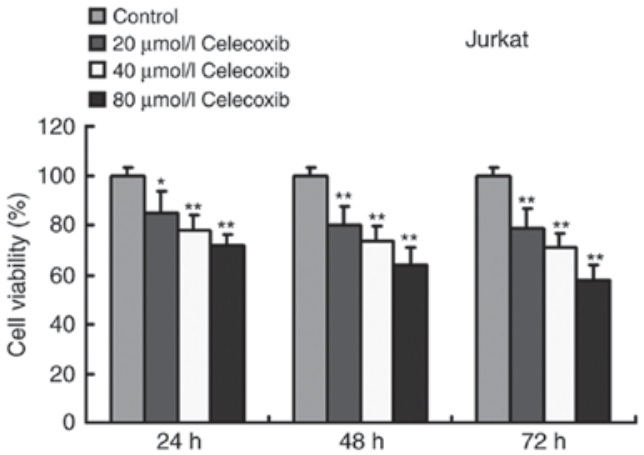

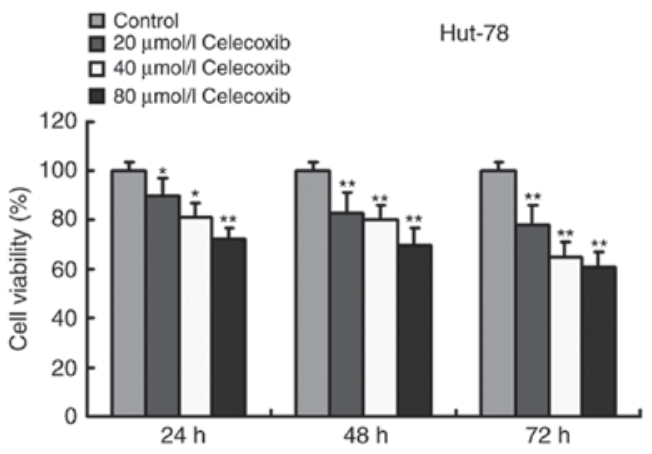

B

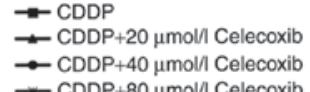

- CDDP $+80 \mu \mathrm{mol} / /$ Celecoxib

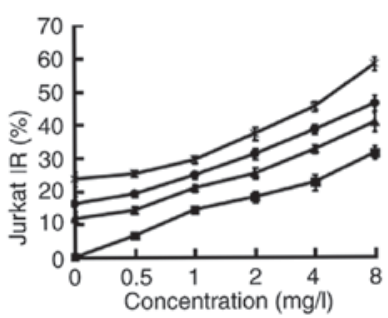

$\because$ CDDP

- CDDP+20 $\mu \mathrm{mol} / \mathrm{l}$ Celecoxib

$\rightarrow$ CDDP $+40 \mu \mathrm{mol} / / \mathrm{Celecoxib}$

— CDDP $+80 \mu \mathrm{mol} / \mathrm{l}$ Celecoxib

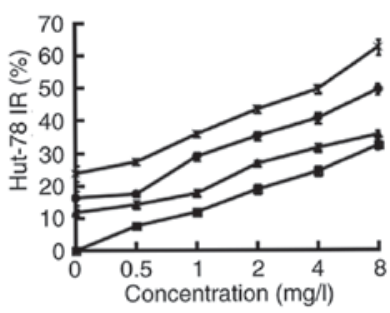

Concentration $(\mathrm{mg} / \mathrm{l})$

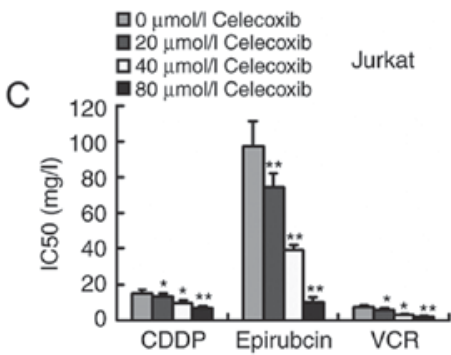

\section{$\rightarrow$ Epirubicin}

ـ Epirubicin $+20 \mu \mathrm{mol} / /$ Celecoxi

$\rightarrow$ Epirubicin $+40 \mu \mathrm{mol} / \mathrm{l}$ Celecoxib

- Epirubicin $+80 \mu \mathrm{mol} / /$ Celecoxib

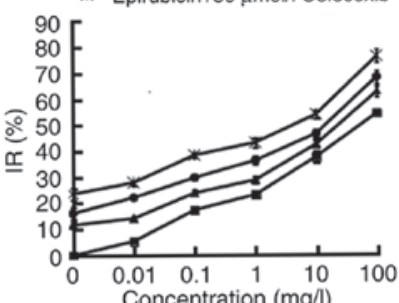

Concentration $(\mathrm{mg} / \mathrm{l})$
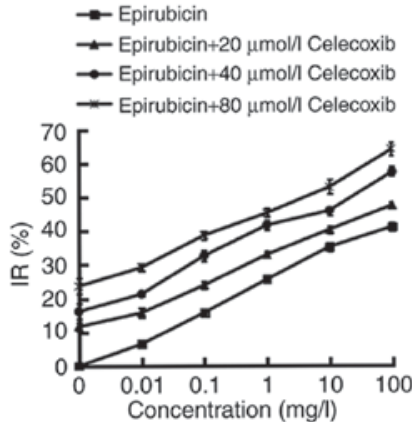

Concentration $(\mathrm{mg} / \mathrm{l})$

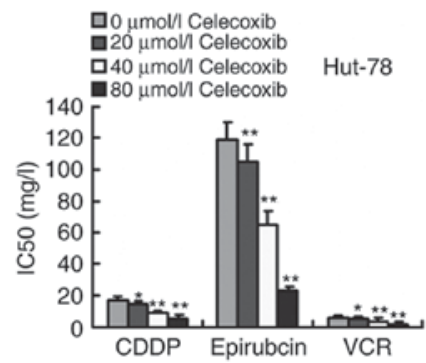

$\because$ VCR

$\approx \mathrm{VCR}+20 \mu \mathrm{mol} / \mathrm{l}$ Celecoxib

$\rightarrow$ VCR+40 $\mu \mathrm{mol} / / \mathrm{C}$ Celecoxib

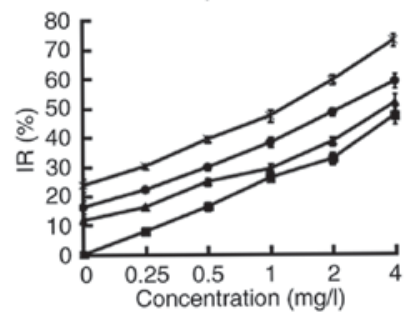

$-\mathrm{VCR}$

—VCR+20 $\mu \mathrm{mol} / \mathrm{l}$ Celecoxib

$\rightarrow \mathrm{VCR}+40 \mu \mathrm{mol} / /$ Celecoxib

— VCR+80 $\mu \mathrm{mol} / \mathrm{l}$ Celecoxib
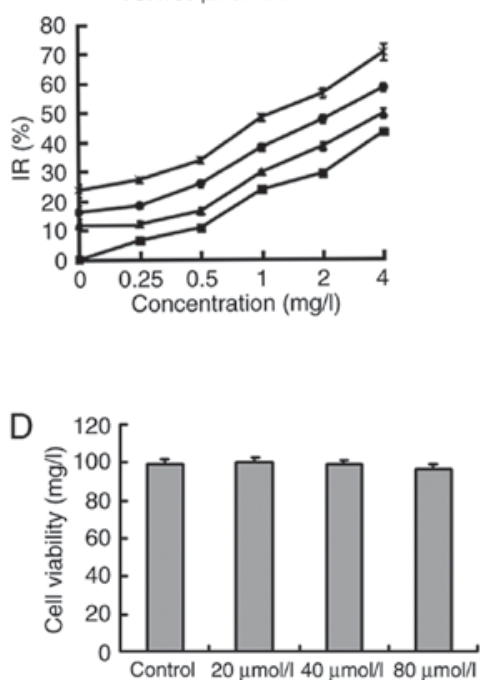

— VCR+80 $\mu \mathrm{mol} / \mathrm{l}$ Celecoxib

Figure 1. Ability of celecoxib to inhibit proliferation and enhance the chemosensitivity of Jurkat and Hut-78 cells to anticancer drugs. (A) The inhibition effect of celecoxib on Jurkat and Hut-78 cells for 24, 48 and $72 \mathrm{~h}$ was determined. (B) The chemotherapy drugs CDDP, epirubicin and VCR dose-dependently inhibited T-cell lymphoma cells proliferation over $24 \mathrm{~h}$. Cells treated with celecoxib were more sensitive to chemotherapy drugs. (C) IC ${ }_{50}$ values of $\mathrm{CDDP}_{\text {, }}$ epirubicin and VCR were decreased in Jurkat and Hut-78 cells treated with celecoxib $(\mathrm{P}<0.05)$. (D) Effect of celecoxib on T cells was determined. The viability of normal $\mathrm{T}$ cells (control) was not reduced following treatment with celecoxib compared with those without celecoxib treatment. Cell viability and $\mathrm{IC}_{50}$ values are presented as the mean \pm standard deviation from three independent experiments. ${ }^{*} \mathrm{P}<0.05$ and ${ }^{* *} \mathrm{P}<0.01$ vs. the control group. $\mathrm{CDDP}$, cis-diamminedichloroplatinum; VCR, vinblastine; $\mathrm{IC}_{50}$, half maximal inhibitory concentration.

was also significantly increased compared with cells treated with chemotherapy agents alone. These data revealed that celecoxib may enhance cytotoxicity of chemotherapy drugs by the pro-apoptotic effect, additionally suggesting that celecoxib is a potential chemosensitizer for T-cell lymphoma treatment.

Celecoxib inhibits the expression of the MDR-associated proteins via the $N F-\kappa B$ signaling pathway. To address the underlying mechanism that may be involved in the celecoxib-mediated pro-apoptotic and chemosensitizing effect, the changes of MDR-associated proteins expression in T-cell lymphoma cells was analyzed. As P-gp, encoded by MDR1, and MRP1 are closely associated with the development of MDR, while Bcl-2 and Bax are important factors involved in the induction of apoptosis, their expression was evaluated in Jurkat and Hut-78 cells treated with celecoxib. The results indicated that the expression levels of Bcl-2, MDR1 and MRP1 mRNA and proteins were significantly downregulated, 

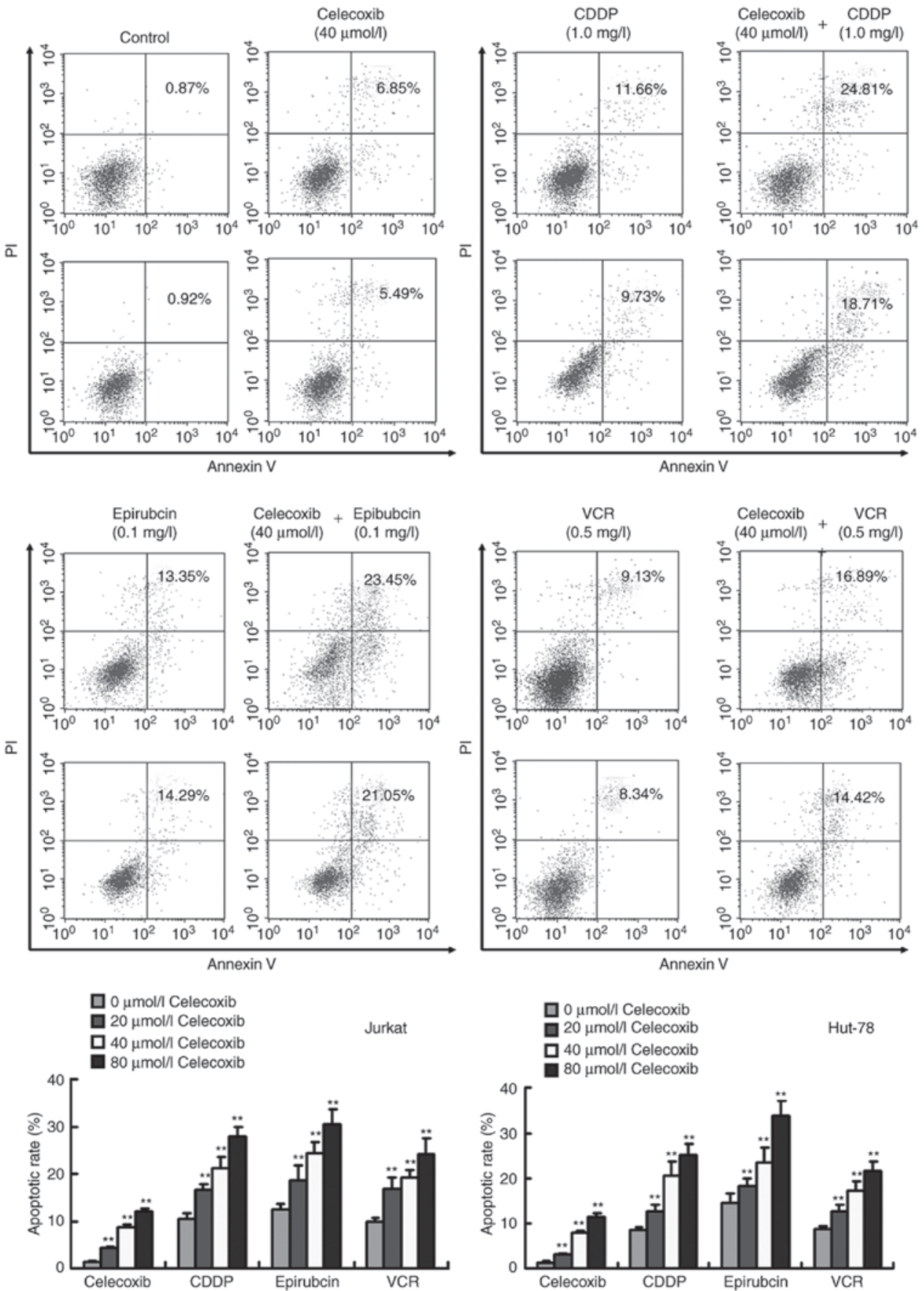

Figure 2. Induction of apoptosis by various chemotherapy drugs in T-cell lymphoma cells treated with or without celecoxib. The effect of celecoxib on the apoptotic rate of Jurkat and Hut-78 cells was detected by flow cytometry analysis. Celecoxib treatment significantly increased the percentage of Annexin V-positive cells compared with that in the control group, when the cells were not treated with chemotherapy agent. Additionally, when Jurkat and Hut-78 cells were treated with CDDP $(0.5 \mathrm{mg} / \mathrm{l})$, epirubicin $(0.25 \mathrm{mg} / \mathrm{l})$ or VCR $(0.01 \mathrm{mg} / \mathrm{l})$, the percentage of Annexin V-positive cells was also significantly higher in cells treated with celecoxib compared with those without celecoxib $(\mathrm{P}<0.01)$. Similar results were obtained in three independent experiments. ${ }^{* *} \mathrm{P}<0.01$ vs. the control group. CDDP, cis-diamminedichloroplatinum; VCR, vinblastine; PI, propidium iodide.

whereas the expression of Bax was upregulated in tumor cells treated with celecoxib compared with those that were not treated with celecoxib ( $\mathrm{P}<0.05$; Fig. $3 \mathrm{~A}$ and $\mathrm{B})$.

Furthermore, the effect of celecoxib on the expression of $\mathrm{p} 65$, which is involved in regulating cell apoptosis and inducing MDR, was assessed. As indicated in Fig. 3A and B, the expression of p65 was decreased significantly in celecoxib-treated Jurkat and Hut-78 cells. It is well-known that the NF-кB P65 subunit participates in activating various downstream genes associated with the regulation of apoptosis and induction of MDR (6-8). Several studies have revealed that Bcl-2 may suppress the activity of multiple pro-apoptotic proteins by binding with P65 $(3,6)$. Additionally, previous studies also confirmed that the majority of the MDR-associated proteins, including P-gp and MRP1, are positively regulated by the $\mathrm{NF}-\kappa \mathrm{B}$ pathway, and that blockade of the NF- $\kappa \mathrm{B}$ pathway may suppress their expression $(6,7)$. Therefore, these results suggested that the celecoxib-mediated pro-apoptotic and 

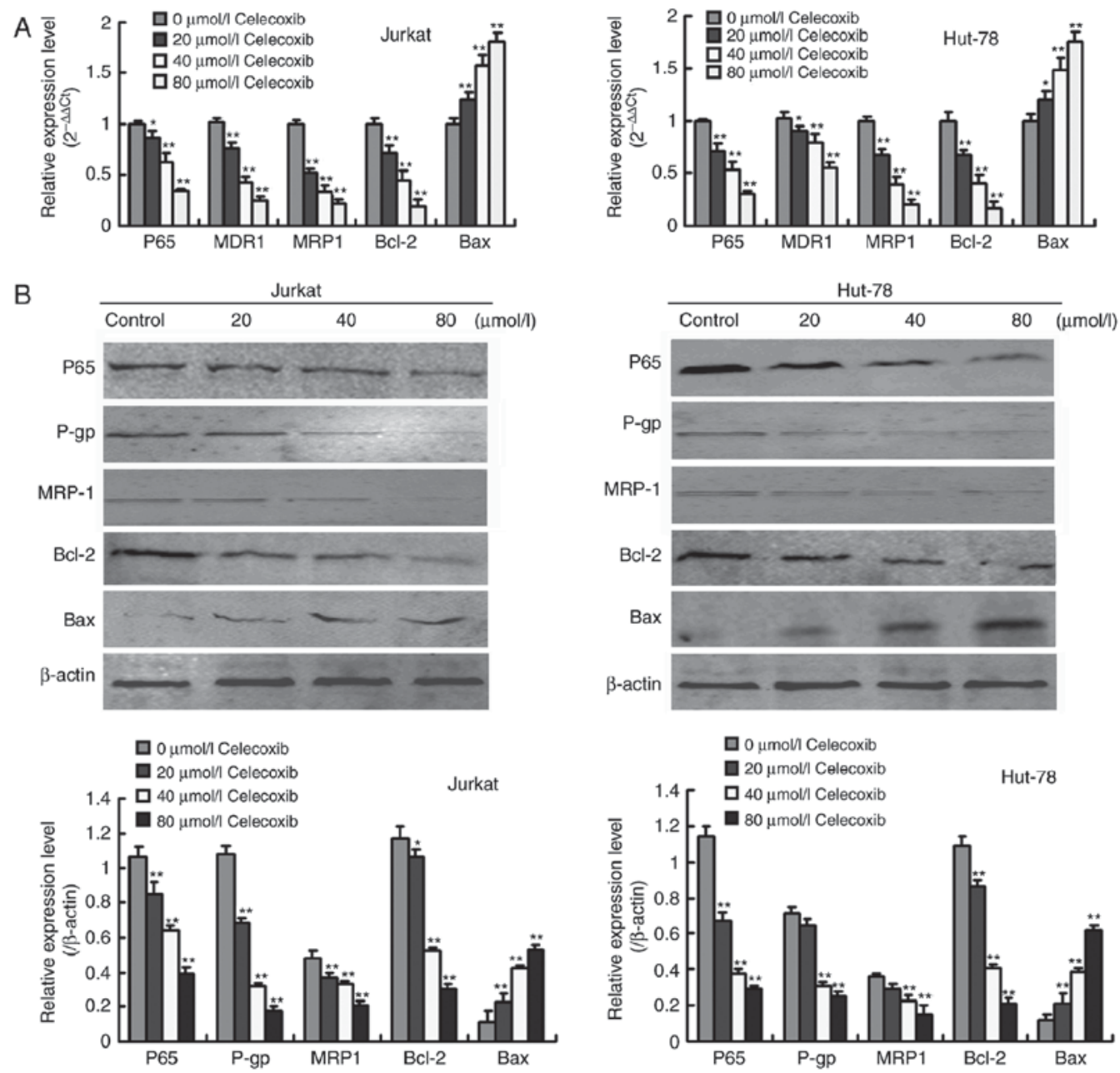

Figure 3. Effect of celecoxib on the expression of proteins associated with chemotherapy sensitivity in Jurkat and Hut-78 cells. (A) Reverse transcription quantitative polymerase chain reaction assays of the expression levels of P65, MDR1, MRP1, Bcl-2 and Bax mRNAs in Jurkat and Hut-78 cells. (B) Western blotting assays of the expression levels of P65, P-gp, encoded by MDR1, MRP1, Bcl-2 and BaX protein expression in Jurkat and Hut-78 cells. $\beta$-actin was used as an internal loading control. The experiments presented are representative of three independent experiments. " $\mathrm{P}<0.05$ and ${ }^{* *} \mathrm{P}<0.01$ vs. the control group. $\mathrm{P} 65$, tumor protein 65; P-gp, P-glycoprotein; MDR1, multidrug resistance protein 1; MRP1, multidrug resistance-associated protein 1; Bcl-2, B-cell lymphoma 2, Bax, Bcl-2-associated X protein.

chemosensitizing effect on $\mathrm{T}$ lymphocytes are associated with decreased expression of MDR-associated proteins Bcl-2, Bax, P-gp and MRP1 via inhibition of the NF-kB pathway.

Celecoxib inhibits the efflux of intracellular Rhodamine-123 in Jurkat and Hut-78 cells. The effect of celecoxib on the exclusion of intracellular Rhodamine-123 by pump proteins was evaluated by a Rhodamine-123 efflux assay. The results of flow cytometry analysis indicated that the intracellular concentration of Rhodamine-123 was significantly increased in Jurkat and Hut-78 cells treated with celecoxib compared with those that were not treated with celecoxib ( $\mathrm{P}<0.01$, Fig. 4), indicating that celecoxib may impair the efflux effect of the P-gp and MRP1 in Jurkat and Hut-78 cells, inhibiting the exclusion and promoting the intracellular accumulation of chemotherapy agents.

\section{Discussion}

At present, T-cell lymphoma has one of the highest mortality rates of all non-Hodgkin lymphoma; the average mortality rate of the patients with T-cell lymphoma remains $>70 \%$ (1). Whilst the traditional chemotherapy strategies have markedly improved in the previous 3 decades, MDR remains a great challenge in lymphoma treatment. It was suggested that the application of anticancer agents may induce the overexpression of various MDR-associated proteins and blockage of apoptosis in tumor cells (7). However, the exact mechanism that induces MDR has not been clarified at present. Strategies of avoiding MDR and improving sensitivity to chemotherapy remain the most critical problems in treatment of T-cell lymphoma.

Whilst celecoxib has been identified as an effective anti-tumor agent, characterized by inhibiting proliferation in a variety of tumor cells (8), little is known about its effect on chemosensitivity in T-cell lymphoma. Previous studies have revealed that celecoxib may prevent chemotherapy drug resistance in digestive and gynecologic carcinomas (9-12), but whether it serves a similar role in T-cell lymphoma has not been determined. The present study demonstrated that celecoxib sensitized Jurkat and Hut-78 cells to various chemotherapy drugs by triggering apoptosis and inhibiting the expression of MDR-associated proteins. 

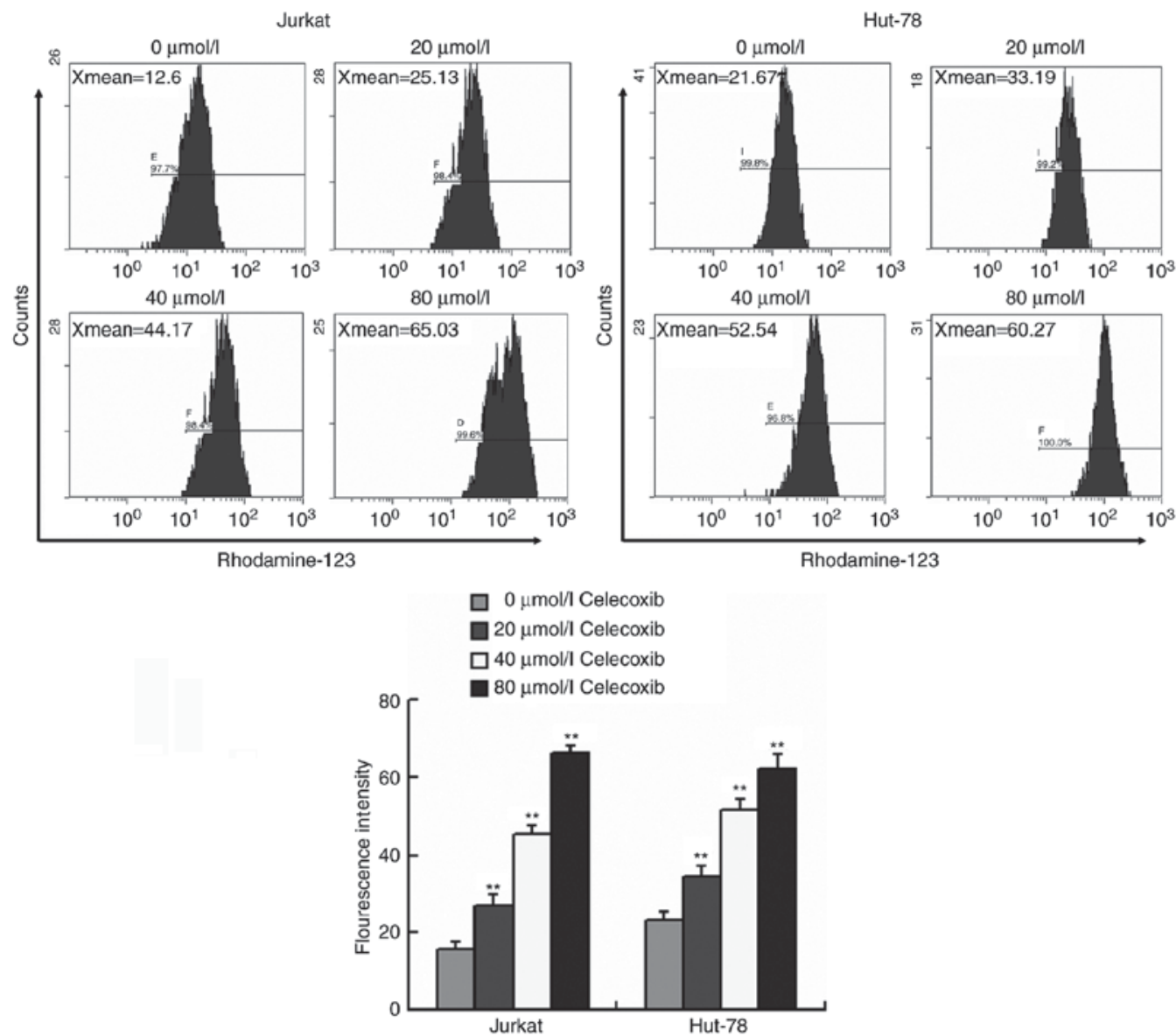

Figure 4. Effect of celecoxib on the intracellular accumulation of Rhodamine-123 in Jurkat and Hut-78 cells. Jurkat and Hut-78 cells were incubated with $5 \mathrm{mg} / \mathrm{ml}$ Rhodamine-123 for $1 \mathrm{~h}$, and intracellular fluorescence was measured to assess the pump function of MDR-associated proteins. The fluorescence intensity indicated the intracellular concentration of Rhodamine-123, as demonstrated by the histogram. Data presented are the mean \pm standard deviation from three independent experiments. ${ }^{* *} \mathrm{P}<0.01$ vs. the control group.

Firstly, the inhibitory effect of celecoxib on T-cell lymphoma cells was investigated using an MTT assay. The results demonstrated that celecoxib significantly suppressed the viability of Jurkat and Hut-78 cells and facilitated the sensitivity of cells to conventional chemotherapy drugs, including CDDP, epirubicin and VCR. The $\mathrm{IC}_{50}$ value of the chemotherapy drugs was significantly decreased in celecoxib-treated cells compared with those that were not treated with celecoxib. Additionally, the results of the flow cytometry analysis demonstrated that celecoxib may induce apoptosis and enhanced cytotoxicity of the chemotherapy drugs in Jurkat and Hut-78 cells. These data demonstrated that the chemotherapy agents combined with celecoxib improved the efficacy of chemotherapy, suggesting that celecoxib may be a potential chemosensitizer in the clinical treatment of T-cell lymphoma. The present study may provide novel insight into the therapeutic effects of celecoxib, and assist in overcoming chemotherapy resistance in T-cell lymphoma.

To additionally explore the pro-apoptotic and chemosensitizing effect of celecoxib on T-cell lymphoma cells, the role of celecoxib in regulating the expression of MDR-associated proteins was investigated. It has been demonstrated previously that the Bcl2 family members protect against the activation of multiple signaling pathways leading to apoptosis of tumor cells, whereas the activation of Bax family members will induce cell apoptosis, indicating that $\mathrm{Bcl} 2 / \mathrm{Bax}$ axis played a crucial part in regulating the common apoptosis pathway (8-10). In the present study, the celecoxib-treated lymphoma cells exhibited significantly decreased expression of Bcl-2 and increased expression of Bax compared with those that were not treated with celecoxib, suggesting that effect on the $\mathrm{Bcl}-2 / \mathrm{BaX}$ protein ratio may be an important contributing factor to celecoxib-induced apoptosis. Additionally, it has been identified that the abnormal expression of P-gp and MRP1 on the surface of the cell membrane may impair tumor chemosensitivity and lead to MDR by removing chemotherapy drugs from tumor cells (13-16). Overexpression of P-gp and MRP1 in tumor tissues has been associated with poor response to clinical chemotherapy in T-cell lymphoma $(15,17)$. The results of the present study also demonstrated that the expression of P-gp and MRP1 was significantly downregulated in Jurkat and Hut-78 cells treated with celecoxib compared with those that were not treated with celecoxib, indicating that celecoxib may inhibit the efflux of intracellular anticancer agents. In addition, the intracellular concentration of Rhodamine-123 in Jurkat and Hut-78 cells treated with celecoxib was significantly increased, indicating that celecoxib weakened the efflux function of P-gp and MRP1.

To elucidate the signaling pathway affected by celecoxib, the effect of celecoxib on the activity of the NF- $\mathrm{KB}$ pathway 
was evaluated. P65, the primary functioning subunit of activated $N F-\kappa B$, is an important indicator for predicting MDR in tumors, as it promotes cell viability, causes apoptosis resistance and enhances expression of various MDR-associated proteins including P-gp and MRP1 (7). Furthermore, previous studies have also confirmed that the expression of $\mathrm{Bcl}-2$ may be directly upregulated by activation of the NF- $\kappa \mathrm{B}$ signaling pathway, thereby inhibiting Bax expression and leading to an anti-apoptotic effect in tumor cells (8-11). In the present study, the results suggested that the expression of $\mathrm{P} 65, \mathrm{Bcl} 2$, P-gp and MRP1 was significantly decreased, while the expression of Bax was increased in celecoxib-treated Jurkat and Hut-78 cells t compared with those that were not treated with celecoxib. Therefore, P65 may be a key factor affected by celecoxib in regulating the expression of the apoptosis- and MDR-associated proteins.

To conclude, the present study identified that celecoxib may induce apoptosis and improve the sensitivity of T-cell lymphoma cells to chemotherapy by decreasing the expression of P-gp, MRP1 and $\mathrm{Bcl}-2 / \mathrm{Bax}$ ratio via the $\mathrm{NF}-\kappa \mathrm{B}$ pathway, and by increasing the intracellular accumulation of anticancer drugs. Celecoxib may therefore be a potential candidate for improving the curative effect of chemotherapy drugs in T-cell lymphomas.

\section{Acknowledgements}

The present study was partially supported by the Natural Science Foundation of China (grant no., 81372200), the Natural Science Foundation of China ofHebeiProvince(grantno.,H2015206376) and the Health and Family Planning Commission of Hebei Province (grant nos., 20150305 and 20160171).

\section{References}

1. Wang C, McKeithan TW, Gong Q, Zhang W, Bouska A Rosenwald A, Gascoyne RD, Wu X, Wang J, Muhammad Z, et al: $I D H 2^{R I 72}$ mutations define a unique subgroup of patients with angioimmunoblastic T-cell lymphoma. Blood 126: 1741-1752, 2015.

2. Fang P, Zhang X, Gao Y, Ding CR, Cui F and Jiao SC: Reversal effect of melanoma differentiation associated gene-7/interleukin-24 on multidrug resistance in human hepatocellular carcinoma cells. Anat Rec 295: 1639-1646, 2012.

3. Futagami S, Suzuki K, Hiratsuka T, Shindo T, Hamamoto T, Ueki N, Kusunoki M, Miyake K, Gudis K, Tsukui T and Sakamoto C: Chemopreventive effect of celecoxib in gastric cancer. Inflammopharmacology 15: 1-4, 2007.
4. Xu HB, Shen FM and Lv QZ: Celecoxib enhanced the cytotoxic effect of cisplatin in chemo-resistant gastric cancer xenograft mouse models through a cyclooxygenase-2-dependent manner. Eur J Pharmacol 776: 1-8, 2016.

5. Livak KJ and Schmittgen TD: Analysis of relative gene expression data using real-time quantitative PCR and the $2^{-\Delta \Delta C \mathrm{~T}}$ method. Methods 25: 402-408, 2001.

6. Yan ZX, Zheng Z, Xue W, Zhao MZ, Fei XC, Wu LL, Huang LM, Leboeuf C, Janin A, Wang L et al: MicroRNA181a is overexpressed in T-cell leukemia /lymphoma and related to chemoresistance. Biomed Res Int 2015: 197241, 2015.

7. Kuo MT, Liu Z, Wei Y, Lin-Lee YC, Tatebe S, Mills GB and Unate $\mathrm{H}$ : Induction of human MDR1 gene expression by 2 -acetylaminofluorene is mediated by effectors of the phosphoinositide 3-kinase pathway that activate NF-kappaB signaling. Oncogene 21: 1945-1954, 2002.

8. Wang L, Kang F, Li J, Zhang J and Shan B: Overexpression of p65 attenuates celecoxib-induced cell death in MDA-MB-231 human breast cancer cell line. Cancer Cell Int 13: 14, 2013.

9. Wang L, Liu LH, Shan BE, Zhang C, Sang MX and Li J: Celecoxib promotes apoptosis of breast cancer cell line MDA-MB-231 through down-regulation of the NF-kappaB pathway. Ai Zheng 28: 569-574, 2009 (In Chinese).

10. Arunasree KM, Roy KR, Anilkumar K, Aparna A, Reddy GV and Reddanna P: Imatinib-resistant K562 cells are more sensitive to celecoxib, a selective COX-2 inhibitor: Role of COX-2 and MDR-1. Leuk Res 32: 855-864, 2008.

11. Liu Z, Duan ZJ, Chang JY, Zhang ZF, Chu R, Li YL, Dai KH, Mo GQ and Chang QY: Sinomenine sensitizes multidrug-resistant colon cancer cells (Caco-2) to doxorubicin by downregulation of MDR-1 expression. PLoS One 9: e98560, 2014.

12. Yan $M$ and Nuriding $H$ : Reversal effect of vitamin $D$ on different multidrug-resistanT cells. Genet Mol Res 13: 6239-6247, 2014.

13. Rauf A, Uddin G, Raza M, Ahmad B, Jehan N, Siddiqui BS, Molnar J, Csonka A and Szabo D: Reversal of multidrug resistance in mouse lymphoma cells by extracts and flavonoids from pistacia integerrima. Asian Pac J Cancer Prev 17: 51-55, 2016.

14. Lu D, Shi HC, Wang ZX, Gu XW and Zeng YJ: Multidrug resistance-associated biomarkers PGP, GST-pi, Topo-II and LRP as prognostic factors in primary ovarian carcinoma. Br J Biomed Sci 68: 69-74, 2011.

15. Zhu WY, Huang YY, Liu XG, He JY, Chen DD, Zeng F, Zhou JH and Zhang YK: Prognostic evaluation of CapG, gelsolin, P-gp, GSTP1, and Topo-II proteins in non-small cell lung cancer. Anat Rec 295: 208-214, 2012.

16. Sakamoto A, Matsumaru T, Yamamura N, Uchida Y, Tachikawa M, Ohtsuki S and Terasaki T: Quantitative expression of human drug transporter proteins in lung tissues: Analysis of regional, gender, and interindividual differences by liquid chromatography-tandem mass spectrometry. J Pharm Sci 102: 3395-3406, 2013.

17. Yoshimori M, Takada H, Imadome K, Kurata M, Yamamoto K, Koyama T, Shimizu N, Fujiwara S, Miura O and Arai A: P-glycoprotein is expressed and causes resistance to chemotherapy in EBV-positive T-cell lymphoproliferative diseases. Cancer Med 4: 1494-1504, 2015. 